\title{
Spatial distribution of Agriophyllum squarrosum Moq. (Chenopodiaceae) in the straw checkerboards at a revegetated land of the Tengger Desert, northern China
}

\author{
HUANG Lei ${ }^{1,2 *}$ \\ ${ }^{1}$ Shapotou Desert Research and Experimental Station, Northwest Institute of Eco-Environment and Resources, Chinese \\ Academy of Sciences, Lanzhou 730000, China; \\ ${ }^{2}$ Key Laboratory of Stress Physiology and Ecology in Cold and Arid Regions of Gansu Province, Lanzhou 730000, China
}

\begin{abstract}
The present study focuses on straw checkerboards established in the Shapotou Desert Research and Experimental Station at the southeastern edge of the Tengger Desert and their effects on the species richness and the abundance of Agriophyllum squarrosu Moq. Specifically, detailed analyses on the spatial distribution of $A$. squarrosum and the related soil properties were carried out at a small scale in the straw checkerboards. $A$. squarrosum is an excellent pioneer plant for revegetation in desert areas. However, the distribution pattern of $A$. squarrosum and the influencing factors have not been sufficiently delineated. The results showed that the species richness and the abundance of $A$. squarrosum were decreased exponentially from the border to the center of the straw checkerboards. At the micro-geomorphological scale, the soil texture, soil organic matter (SOM), soil nutrients (nitrogen, phosphorus and potassium), and soil infiltration rate in the topsoil tended to increase from the center to the border within a straw checkerboard, while soil moisture presented an opposite tendency. The soil seed bank of $A$. squarrosum, soil bulk density, electrical conductivity, sand content, $\mathrm{CaCO}_{3}$ accumulation, and $\mathrm{pH}$ showed no significant difference $(P>0.05)$ between the border and the center of the straw checkerboards. Multiple linear regression analysis indicated that the abundance of $A$. squarrosum was mainly determined by the concentrations of SOM, nitrogen, and the infiltration rate, implying that nutrient acclimation was the optimal competitive strategy of $A$. squarrosum for surviving in a barren natural environment of an arid desert region.
\end{abstract}

Keywords: Agriophyllum squarrosum; seed banks; soil moisture; soil infiltration rate; nutrient acclimation

Citation: HUANG Lei. 2017. Spatial distribution of Agriophyllum squarrosum Moq. (Chenopodiaceae) in the straw checkerboards at a revegetated land of the Tengger Desert, northern China. Journal of Arid Land, 9(2): 176-187. doi: $10.1007 / \mathrm{s} 40333-017-0010-\mathrm{x}$

\section{Introduction}

Vegetation spatial patterns are considered as common and well-defined characteristics of many landscapes (Foti and Ramírez, 2013). The spatial patterns of vegetation are the results of the interaction between biotic factors and abiotic factors and also the results of long-term vegetation successions (Li et al., 2007, 2013). Vegetation spatial patterns in arid desert regions can be either periodic or random (Borgogno et al., 2009). For example, in the Chihuahuan Desert, covering parts of Mexico and the United States, in the Negev Desert in southern Israel, and in other water-limited areas, vegetation distributions generally exhibit multitude patterns, such as banded,

*Corresponding author: HUANG Lei (E-mail: mathecology@163.com)

Received 2015-12-09; revised 2016-06-21; accepted 2016-07-01

(C) Xinjiang Institute of Ecology and Geography, Chinese Academy of Sciences, Science Press and Springer-Verlag Berlin Heidelberg 2017 
spotted, or labyrinthine (Rietkerk and Van de Koppel, 2008; Foti and Ramírez, 2013). Such vegetation patterns attracted numerous researchers in recent decades (Klausmeier, 1999; HilleRisLambers et al., 2001; Rietkerk et al., 2004) and many of those researchers focused on the empirical descriptions or on the pattern formation models (Kéfi et al., 2007; Sherratt, 2013). However, it is still difficult to predict the actual spatial distribution of vegetation under the complex and dynamic behavior of plant communities across a range of spatial and temporal scales (Rowe and Sheard, 1981; Li et al., 2013). Therefore, these difficulties are calling for identifying the key limiting factors in plant spatial pattern formation. Some previous studies demonstrated that the spatial distribution of natural plant communities is determined by the relationships between abiotic factors (e.g., climate, geology, topography and soils) and biotic factors (e.g., ecological niche, diffusion capacity, interspecific interaction, etc.) at different spatial and temporal scales (Eccles et al., 1999; Bolker et al., 2003; Schurr et al., 2004; Monzeglio and Stoll, 2005). At regional scales, climate determines vegetation types. However, at small scales, microhabitats, soil nutrients and soil moisture may determine the vegetation distribution patterns (Woodward and Mckee, 1991; Burke, 2001; Li et al., 2010).

Agriophyllum squarrosum (L.) Moq. (Chenopodiaceae) is an annual psammophyte that is widely distributed in the temperate sandy deserts in Central Asia (Tobe et al., 2005; Miao et al., 2013). This species is often found on bare sandy patches of moving and semi-fixed sand dunes. The seeds of A. squarrosum usually germinate in the period of May to August and the plant flowers in September (Wang et al., 1998; Ma and Liu, 2008). The species has evolved in a range of physiological and morphological characteristics to allow itself to be a pioneer species in sandy desert areas (Bai et al., 2004). Furthermore, the latest study showed that the species may be a potential crop well adapting to the projected future climate changes (Chen et al., 2014). Therefore, quantifying the distribution patterns of $A$. squarrosum and its influencing factors may also be of economic significance. Although some studies have been conducted to investigate the biological characteristics, seed morphology and growth adaptation of $A$. squarrosum (Nemoto and Lu, 1992; Bai et al., 2004), the spatial distribution patterns of the plant community at small scales (a few meters) are not well delineated (Miao et al., 2013). These small-scale changes of vegetation patterns usually have direct effects on infiltration, runoff, erosion, water storage, and catenary sequences of soils and nutrients ( $\mathrm{Li}$ et al., 2010), thus creating various microhabitats and enhancing heterogeneity in desert ecosystems ( $\mathrm{Li}, 2012)$.

The present study focuses on straw checkerboards established in the Shapotou Desert Research and Experimental Station at the southeastern edge of the Tengger Desert and their effects on the species richness and the abundance of A. Squarrosum. Specifically, detailed analyses on the spatial distribution of $A$. squarrosum and the related soil properties were carried out at a small scale in the straw checkerboards established in 2010. The specific objectives of this study were to determine the spatial heterogeneity of A. squarrosum distribution and the relationships of plant abundance with the re-allocation of topsoil parameters induced by the straw checkerboards. The study will elevate our understanding regarding the influence of micro-geomorphology on plant distribution and expand our knowledge regarding plant adaptation strategies to drought stress in extremely arid desert systems.

\section{Materials and methods}

\subsection{Study area}

The study area is located in the Shapotou Desert Research and Experimental Station at the southeastern edge of the Tengger Desert $\left(37^{\circ} 32^{\prime} \mathrm{N}, 105^{\circ} 02^{\prime} \mathrm{E}\right.$; Fig. 1). The annual mean temperature is $9.6^{\circ} \mathrm{C}$ and the mean annual precipitation is $188.2 \mathrm{~mm}$ (according to meteorological records from 1956 to 2009) with nearly 70\% falling between June and September. The potential evapotranspiration during the growing season (May to September) is $2300-2500 \mathrm{~mm}$. The 
minimum and maximum average monthly relative humidity were $33.0 \%$ and $54.9 \%$ in April and August, respectively. The average annual wind velocity is $2.6 \mathrm{~m} / \mathrm{s}$, and the windy season is from preceding September to succeeding April. The underground water table is greater than $80 \mathrm{~m}$ and is thus not able to support natural vegetation. Hence, precipitation is the main source of water for plant growth (Huang et al., 2014; Zhang et al., 2015) in this area.

To protect the Baotou-to-Lanzhou railway line from the risk of sand burial in the Shapotou region, a sand-binding revegetation protective system was established (Fig. 1). Sand barriers of 1 $\mathrm{m} \times 1 \mathrm{~m}$ straw squares laid out in the checkerboards pattern were established. The straw was inserted at a depth of $0.15-0.20 \mathrm{~m}$ and protruded approximately $0.10-0.15 \mathrm{~m}$ above the dune surface to increase surface roughness and reduce wind erosion. These checkerboards could stay intact for as long as 4-5 years because natural decomposition was very slow under this dry condition ( $\mathrm{Li}$ et al., 2006).
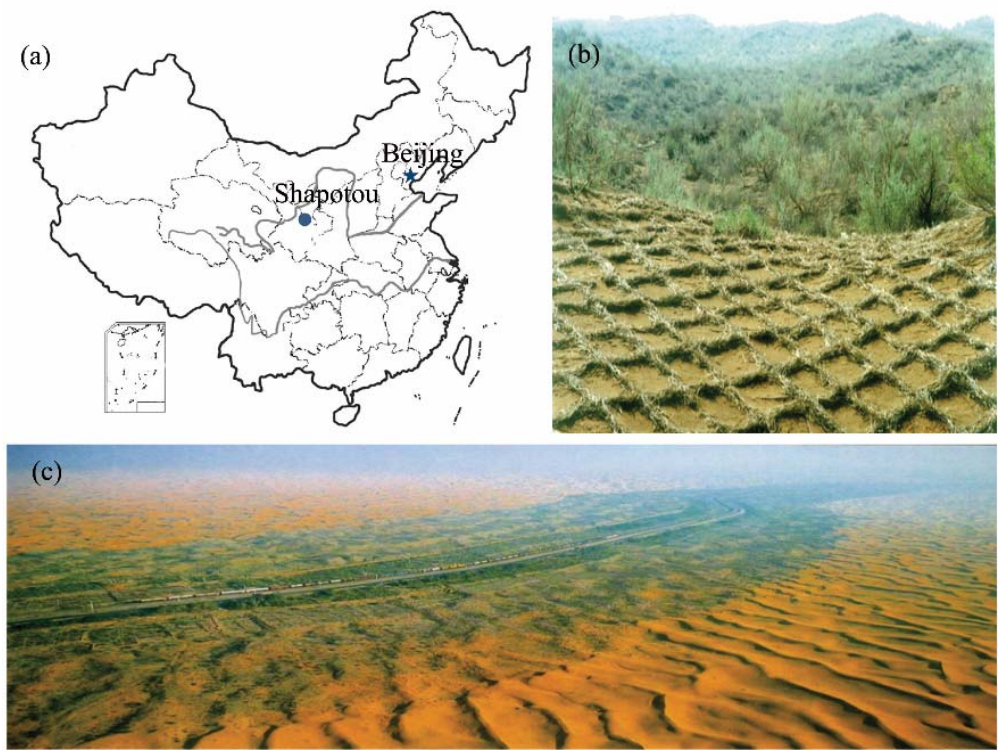

Fig. 1 The study site in the Shapotou region of the Tengger Desert, northern China (a); straw checkerboards used for stabilizing mobile dunes (b); and Shapotou sand-binding revegetation protective system (c)

\subsection{Soil sampling and analysis}

In this study, straw checkerboards were established in 2010 . Ten straw square plots $(1 \mathrm{~m} \times 1 \mathrm{~m}$ each) were randomly selected for soil sampling and vegetation surveying (Fig. 2). For comparison

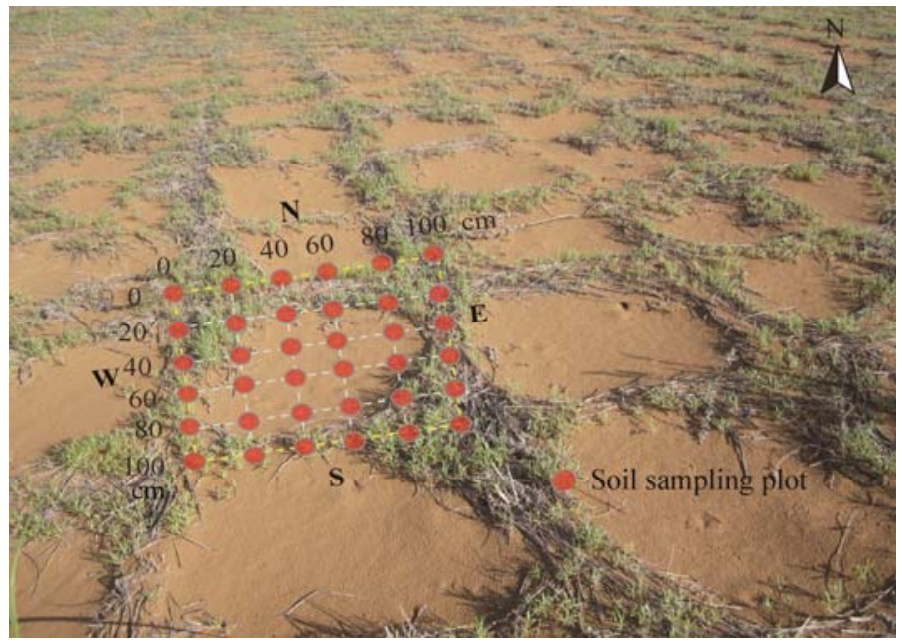

Fig. 2 Straw checkerboards and sampling plots 
ten sandy plots $(1 \mathrm{~m} \times 1 \mathrm{~m}$ each $)$ and ten straw square plots without plant were chosen as the control groups in the adjacent moving sand dunes. The field investigation was conducted in 2013. In each $1 \mathrm{~m} \times 1 \mathrm{~m}$ straw square, 36 soil samples were taken (Fig. 2). They were uniformly arranged in $0.2-\mathrm{m}$ vertical and horizontal spacings. Samples were taken from the topsoil at the depth of 0-10 cm along each vertical line from west to east and then mixed thoroughly. That is, totally 6 mixed samples for each square and 10 replications for each mixed sample were obtained. Air-dried soil samples were put through a $2.0-\mathrm{mm}$ sieve for further analysis. Soil texture was determined by the pipette method (Loveland and Walley, 2000); $\mathrm{pH}$ values were measured by a calibrated $\mathrm{pH}$ meter (PHS-4, Jiangsu Manufactory of Electrical Analysis Instruments, Jiangyin, China) in a soil-water suspension with a ratio of 1:5; and soil organic matter (SOM) was determined by the dichromate oxidation method of Walkley-Black (Nelson and Sommers, 1982). Soil nitrogen $(\mathrm{N})$ was measured using a Kjeltec System-1026 distilling unit (Tecator AB, Höganäs, Sweden), and soil phosphorus (P) and potassium (K) were measured using standard methods for observation and analysis developed by the Chinese Ecosystem Research Network (CERN; Liu, 1996). Electrical conductivity (EC) was measured by a portable conductivity meter (Cole-Parmer Instrument Co., IL, USA) and soil soluble salts were analyzed using methods described by the Nanjing Institute of Soil Research (1978). These parameters were selected because they may be potential factors to explain the distribution pattern of $A$. squarrosum.

Seed banks were sampled in late April 2013, just prior to the natural germination of the seeds. By digging out soil from the same soil sampling plots in Figure 2, the samples were collected with a $7.0-\mathrm{cm}$-diameter corer pressed into the ground to a depth of $5.0 \mathrm{~cm}$, and 36 soil sampling cores per straw squares were collected along each vertical line and then mixed. After removing gravel, litter, and roots, the soil samples from each soil core were placed separately in cloth bags, transported to a greenhouse and then spread out into a thin layer (approximately $2.0-\mathrm{cm}$ thick) on plastic trays for germination. The soil samples were sprinkled with water at 19:00 every day. The seedlings were marked with signed tacks and counted once they germinated on a daily basis, and the seedlings were removed as soon as they were identified (Wang et al., 2010). This was repeated until no more seedlings remained. The number of seedlings was converted into density ( $\left.\mathrm{seeds} / \mathrm{m}^{2}\right)$ for analysis.

Precipitation was recorded using a tipping bucket-type rain gauge (Casella). Meteorological factors, such as air temperature, vapor pressure and relative humidity were measured by the eddy covariance (HMP45C, Vaisala Inc., Helsinki, Finland) which was railed $50 \mathrm{~m}$ away from the sampling plots. Soil moisture in the surface soil (depth, $0-10 \mathrm{~cm} ; 0.1 \mathrm{~m} \times 0.1 \mathrm{~m}$ grid; 100 points per $1 \mathrm{~m} \times 1 \mathrm{~m}$ quadrat) was measured by a time domain reflectometry (HH2 moisture meter, Delta-T Devices Ltd., Cambridge, UK) for half a month during the experimental period. A minidisc infiltrometer (MDI, Decagon Devices, Inc., Pullman, WA, USA) was used for assessing the relative infiltration rate. Infiltration measurement was performed at the negative pressure head $\mathrm{h}_{0}=-2.0 \mathrm{~cm}$ with the MDI, and the water volume was manually recorded at 1-min intervals until steady-state conditions were reached. The measured point was located at $0,20,40,60,80$ and 100 $\mathrm{cm}$ along the border of the straw checkerboards. The infiltration rate was calculated from a graph of cumulative infiltration vs. the square root of time, where the slope represents the infiltration rate (Gordillo-Rivero et al., 2014). For each measured point, the species richness (the number of species per plot), abundance (total number of $A$. squarrosum per plot) were recorded.

\subsection{Statistical analysis}

One-way analysis of variance (ANOVA) and Fisher's least significant difference (LSD) were used to test the significance in different distances from the border of the straw checkerboards. Multiple stepwise linear regression analyses of the plant abundance against soil moisture and other soil parameters among different sites around the straw checkerboards were performed using SPSS 13.0 (SPSS 13.0 Inc., Chicago, IL, USA). Graphic plotting was conducted with Origin 7.0 (OriginLab Corporation, Northampton, MA, USA) and MATLAB (The MathWorks Inc., Natick, Massachusetts, USA) software. 


\section{Results}

\subsection{Spatio-temporal heterogeneity of $A$. squarrosum distribution}

The annual precipitation was $125.5 \mathrm{~mm}$ in 2013 and mainly concentrated in July $(57.9 \mathrm{~mm})$. The monthly average air temperature and vapor pressure reached peak values in July as well. But the relative humidity decreased to its minimum in April, then gradually increased to its maximum in August and then declined slowly (Fig. 3a). The species richness and the abundance of $A$. squarrosum in the straw checkerboards and sand dunes both exhibited single-peak curves with peak values appeared in July and gradually decreased from August to December (Figs. 3b and c). The differences of species richness and the abundance of $A$. squarrosum in the straw checkerboards and the sand dunes in different months were significant $(P<0.05)$. But from preceding October to succeeding March, the differences of species richness between the straw checkerboards and the sand dunes were not significant $(P>0.05)$, while the differences of $A$. squarrosum abundance between the straw checkerboards and the sand dunes were significant $(P<0.05)$, meaning that straw checkerboards can facilitate the colonization of the pioneer species A. squarrosum. The seedling of $A$. squarrosum was mainly distributed along the border of the straw checkerboards, while almost no herb plant was appeared in the center. The plant density difference between the border and the center of checkerboards was significant $(P<0.05)$. The average abundance of $A$. squarrosum along the border $(0$ and $100 \mathrm{~cm})$, in the marginal middle (20 and $80 \mathrm{~cm})$ and in the center $(40$ and $60 \mathrm{~cm})$ was $183.19( \pm 13.46), 12.45( \pm 1.32)$ and $1.75( \pm 0.02)$ plants $/ \mathrm{m}^{2}$, respectively, and decreased exponentially with distance from the border to the center (Fig. 3d).
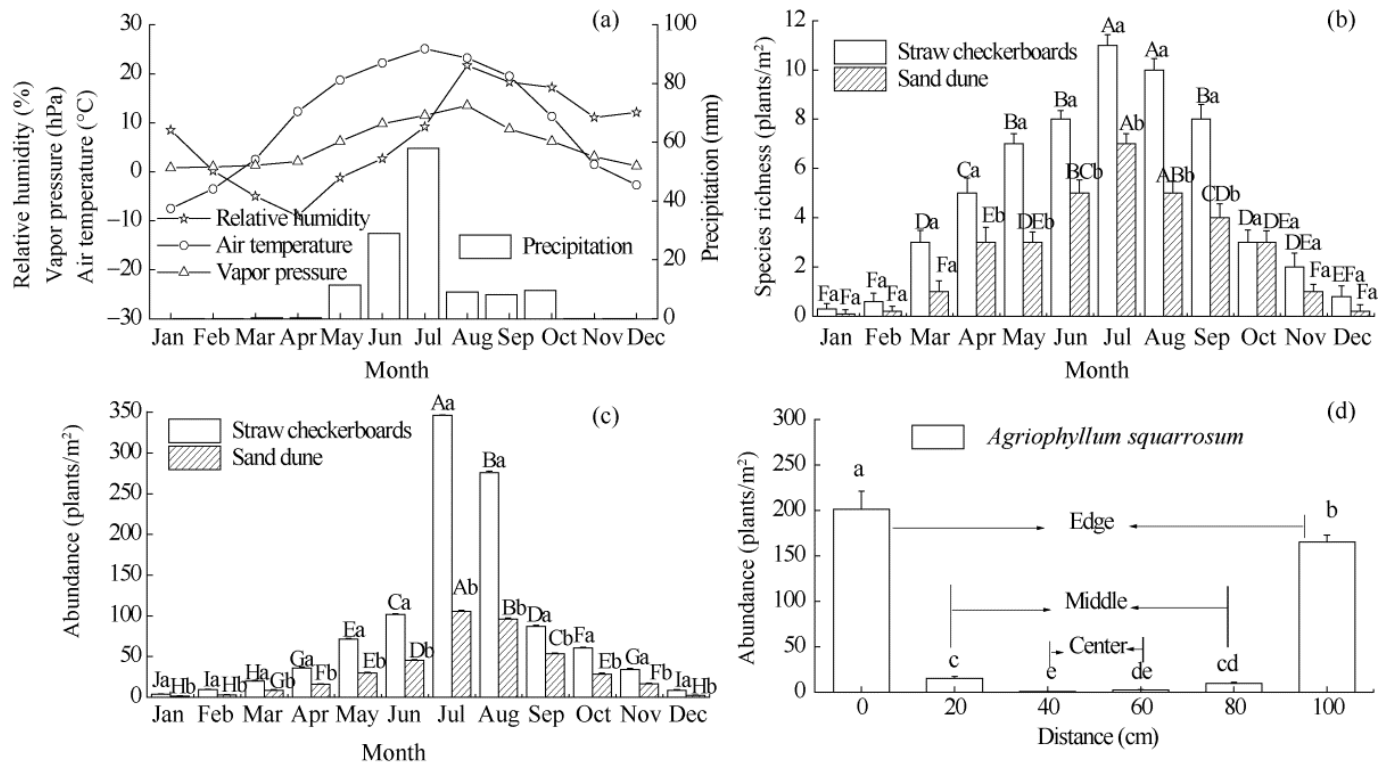

Fig. 3 Monthly precipitation, average air temperature, vapor pressure, and relative humidity in 2013 (a), species richness (b), abundance of $A$. squarrosum in the straw checkerboards and in the sand dunes during our experimental period (January to December 2013 ; c), and changes in the abundance $(n=10)$ of $A$. squarrosum at different distances in the straw checkerboards (d). Plot size was $1 \mathrm{~m} \times 1 \mathrm{~m}$. Bars mean standard errors. In Figures $3 \mathrm{~b}$ and $\mathrm{c}$, different capital letters indicate significant differences in different months $(P<0.05)$; and different lowercase letters denote significant differences between the straw checkerboards and the sand dunes $(P<0.05)$. In Figure $3 \mathrm{~d}$, different lowercase letters indicate significant differences at different distances within a straw checkerboard $(P<0.05)$.

\subsection{Seed banks}

Germinated seeds of 11 species were recorded, including A. squarrosum, Corispermum mongolicum, Corispermum patelliforme, Eragrostis minor, Bassia dasyphylla, Psammochloa 
villosa, Allium mongolicum, Corispermum hyssopifolium, Salsola ruthenica, Egletes humifusa, and Tribulus terrester. As seen in Figure 4, the average soil seed banks along the border of the straw checkerboards had the highest seedling density $\left(531.43( \pm 6.99)\right.$ seeds $\left./ \mathrm{m}^{2}\right)$ and the banks decreased with the distance from the border to the center $\left(427.52( \pm 7.41)\right.$ seeds $/ \mathrm{m}^{2}$ for the border and $303.65( \pm 2.17) \mathrm{seeds} / \mathrm{m}^{2}$ for the center). The average soil seed densities among the border $(0$ and $100 \mathrm{~cm}$ ), the marginal middle $(20$ and $80 \mathrm{~cm}$ ) and the center $(40$ and $60 \mathrm{~cm}$ ) were significantly different $(P<0.05)$. A. squarrosum was the most dominant species, and the soil seed bank of $A$. squarrosum along the border $\left(301.50( \pm 3.35) \mathrm{seeds} / \mathrm{m}^{2}\right)$ was more abundant than it was in the marginal middle $\left(238.45( \pm 2.75)\right.$ seeds $\left./ \mathrm{m}^{2}\right)$ and in the center $\left(226.51( \pm 2.43) \mathrm{seeds} / \mathrm{m}^{2}\right)$, but no significant difference between the marginal middle and the center was found $(P>0.05)$.

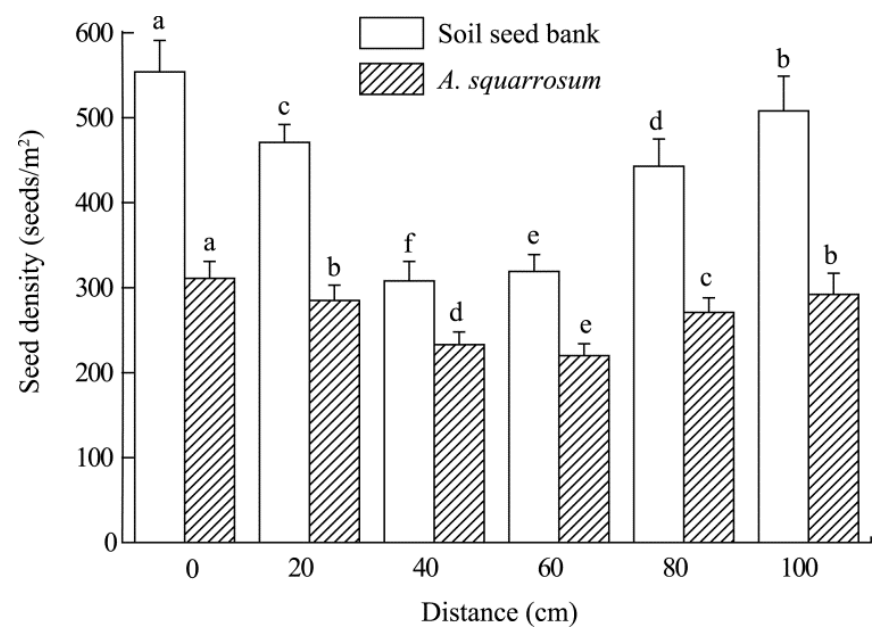

Fig. 4 Density of the soil seed banks and of $A$. squarrosum at different distances in a straw checkerboard. Different lowercase letters indicate significant differences in seed density at different distances from the border to the center $(P<0.05)$. Bars mean standard errors.

\subsection{Re-allocation of topsoil parameters induced by the straw checkerboards}

Micro-geomorphological features strongly influence the spatial re-allocation of the soil parameters. The percentage of silt and clay particles in the soil decreased from the border to the center of the straw checkerboards, while the sand content increased. However, the differences of soil textures at different points were not significant $(P>0.05$; Fig. 5a). Similarly, SOM and the contents of soil nutrients, such as total N, P and $\mathrm{K}$, were also higher along the border and then decreased inward; the differences among the border $(0$ and $100 \mathrm{~cm})$, the marginal middle $(20$ and $80 \mathrm{~cm})$ and the center $(40$ and $60 \mathrm{~cm})$ were significant $(P<0.05)$. For soil bulk density, $\mathrm{pH}$, total salt, $\mathrm{CaCO}_{3}$ and $\mathrm{EC}$, there was almost no difference between different sites within the straw checkerboards ( $P>0.05$; Figs. $5 \mathrm{~b}$ and 6$)$. A plot of the cumulative infiltration from the minidisc infiltrometer was shown in Figure 7. The border of the straw checkerboards $(0$ and $100 \mathrm{~cm})$ had the highest cumulative infiltration rate of $4.46( \pm 0.12)$ and $4.40( \pm 0.11) \mathrm{cm} / \mathrm{s}$ in comparison with the marginal middle $(20$ and $80 \mathrm{~cm}$ ) and with the center $(40$ and $60 \mathrm{~cm})$, respectively. The highest infiltration rate occurred along the border, and followed by the marginal middle and then the center of the straw checkerboards. However, soil moisture in the center of the straw checkerboards had the highest value of $0.41( \pm 0.02) \mathrm{m}^{3} / \mathrm{m}^{3}$ (Fig. 8a). To illustrate the effect of soil moisture on plant abundance, we removed A. squarrosum plants and the soil moisture showed a rather observable increasing tendency from the border to the center (Fig. 8b). The highest soil moisture $\left(0.05( \pm 0.02) \mathrm{m}^{3} / \mathrm{m}^{3}\right)$ also occurred in the center of the straw checkerboards and then decreased outward; the lowest soil moisture was found along the border that ranged from 0.025 $( \pm 0.01)$ to $0.03( \pm 0.01) \mathrm{m}^{3} / \mathrm{m}^{3}$. However, there was no significant difference between the plots with and without the plants $(P>0.05)$, although the average soil moisture in the straw checkerboards without plants was slightly higher than it was in the plots with plants (Fig. 8b). 

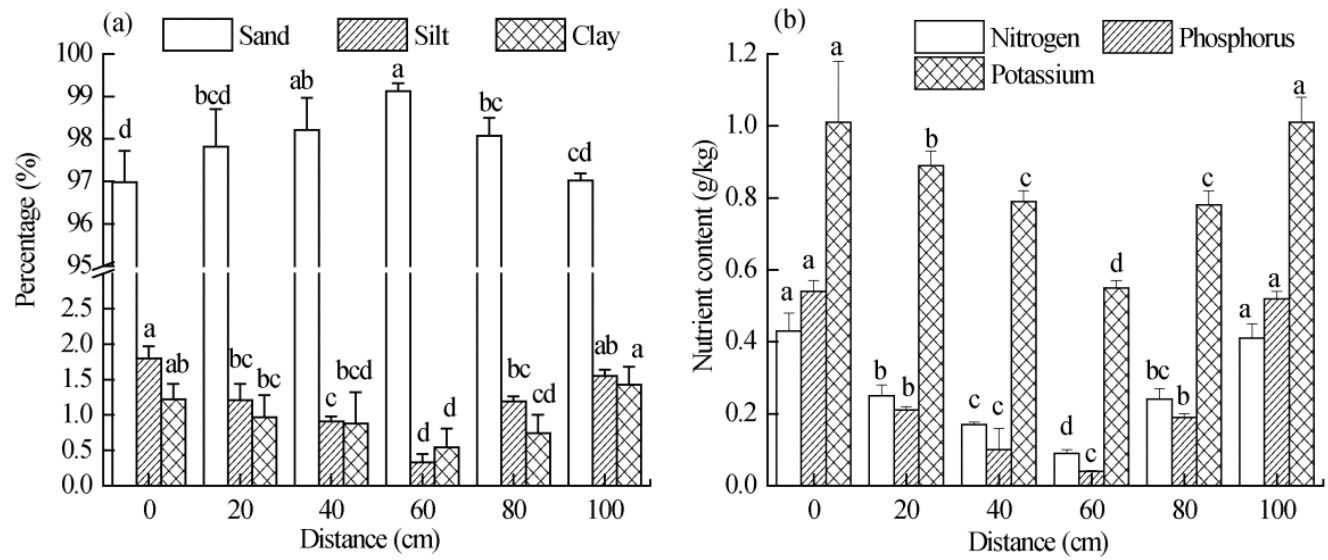

Fig. 5 Contents of soil texture (a) and soil nutrients (b) at different distances in the straw checkerboards. Different lowercase letters indicate significant differences at different distances $(P<0.05)$. Bars mean standard errors.

(a)
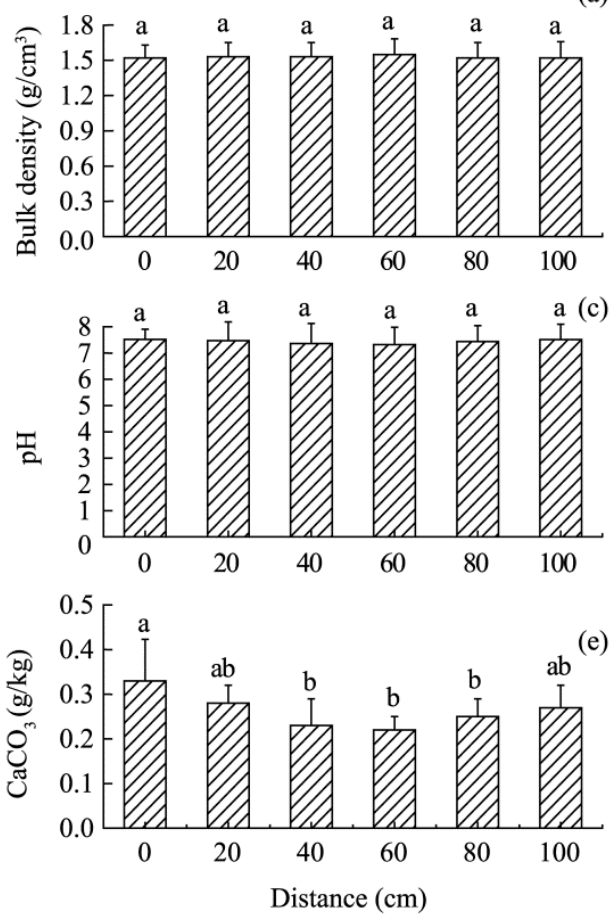

(b)
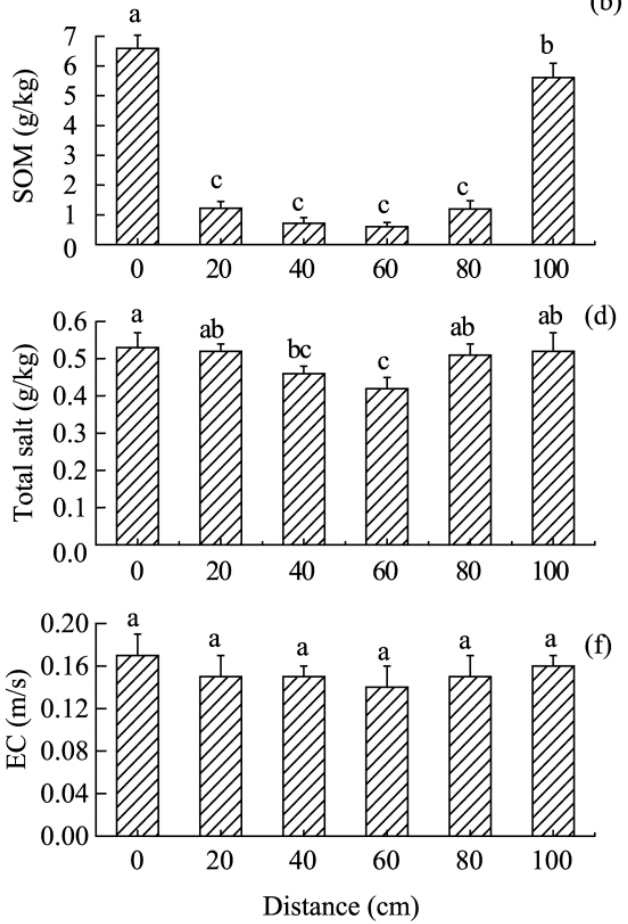

Fig. 6 Changes in soil properties at different distances within a straw checkerboards. SOM, soil organic matter; EC, electrical conductivity. Different lowercase letters indicate significant differences at different distances $(P<0.05)$. Bars mean standard errors.

\subsection{Correlation between plant abundance and soil parameters}

A correlation analysis (Table 1) indicated that the abundance of $A$. squarrosum was significantly and positively correlated with SOM and total $\mathrm{N}$ at $P<0.05$ level but was only weakly correlated with soil seed banks and the other soil parameters (including the silt and clay contents, $\mathrm{P}, \mathrm{K}, \mathrm{pH}$, $\mathrm{CaCO}_{3}$ and $\mathrm{EC}$, and the infiltration rate). Furthermore, plant abundance was highly negatively correlated with sand content, soil moisture and soil bulk density. In addition, there were also inter-dependencies among the various soil physical-chemical parameters at a small scale. For instance, soil water contents in the straw checkerboards were negatively correlated with most of 


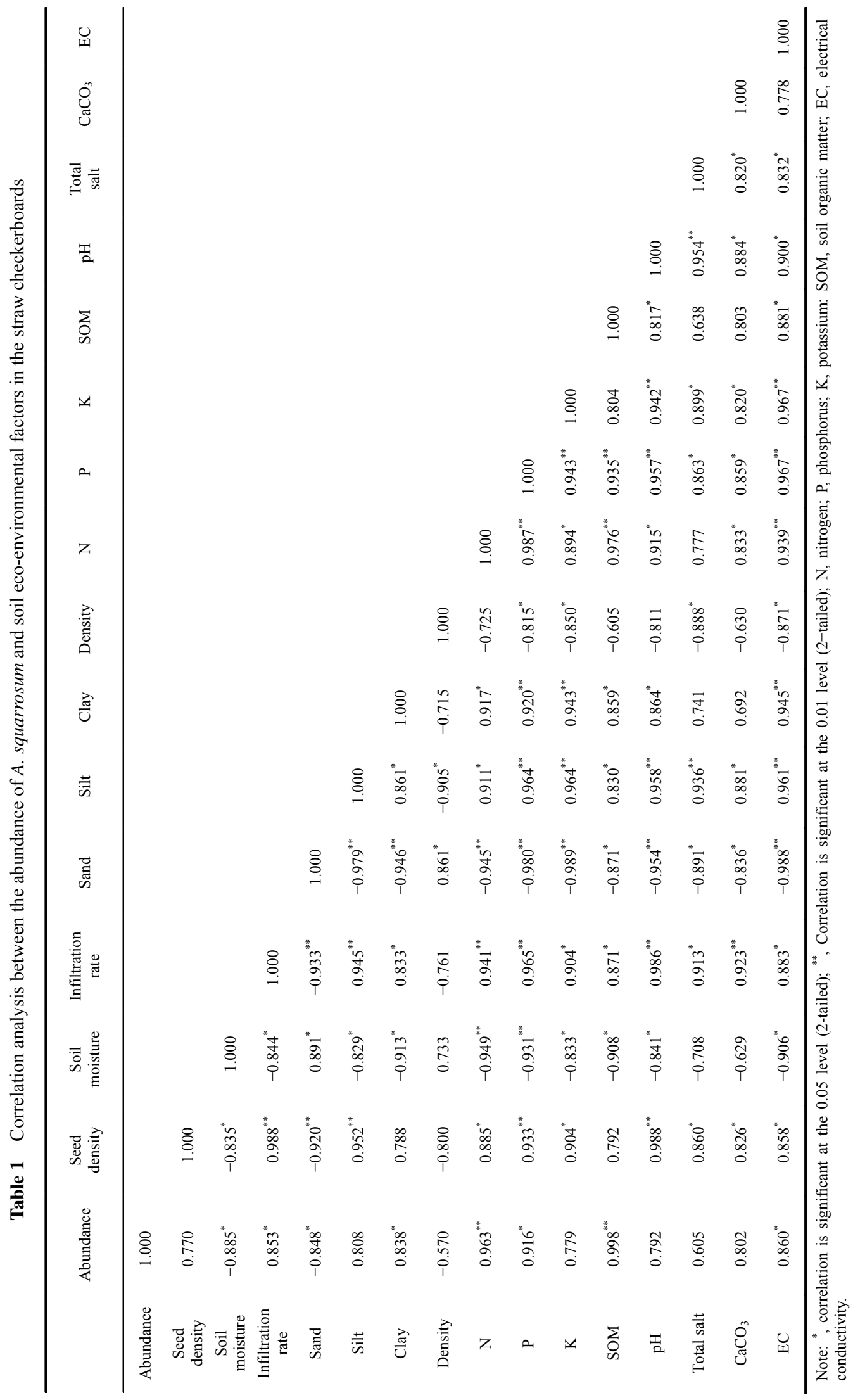


the soil parameters in the topsoil, such as the infiltration rate, clay and silt contents, and soil nutrients. The seed banks were mainly related with the infiltration rate, sand and silt contents, total $\mathrm{P}$ and $\mathrm{pH}$. The infiltration rate was mainly related with the silt and clay contents, $\mathrm{N}, \mathrm{P}, \mathrm{pH}$, and $\mathrm{CaCO}_{3}$. Soil textures, such as the contents of sand, silt, and clay, were mainly related with soil nutrients, $\mathrm{pH}$ and $\mathrm{EC}$. The optical regression model is shown in the following equation:

Plant abundance $=-39.154+42.52 \mathrm{SOM}+123.529 \mathrm{~N}+94.683$ Infiltration rate $\left(R^{2}=0.997\right)$.

This equation indicated that the abundance of $A$. squarrosum was mainly determined by the contents of SOM, total $\mathrm{N}$, and soil infiltration rate.
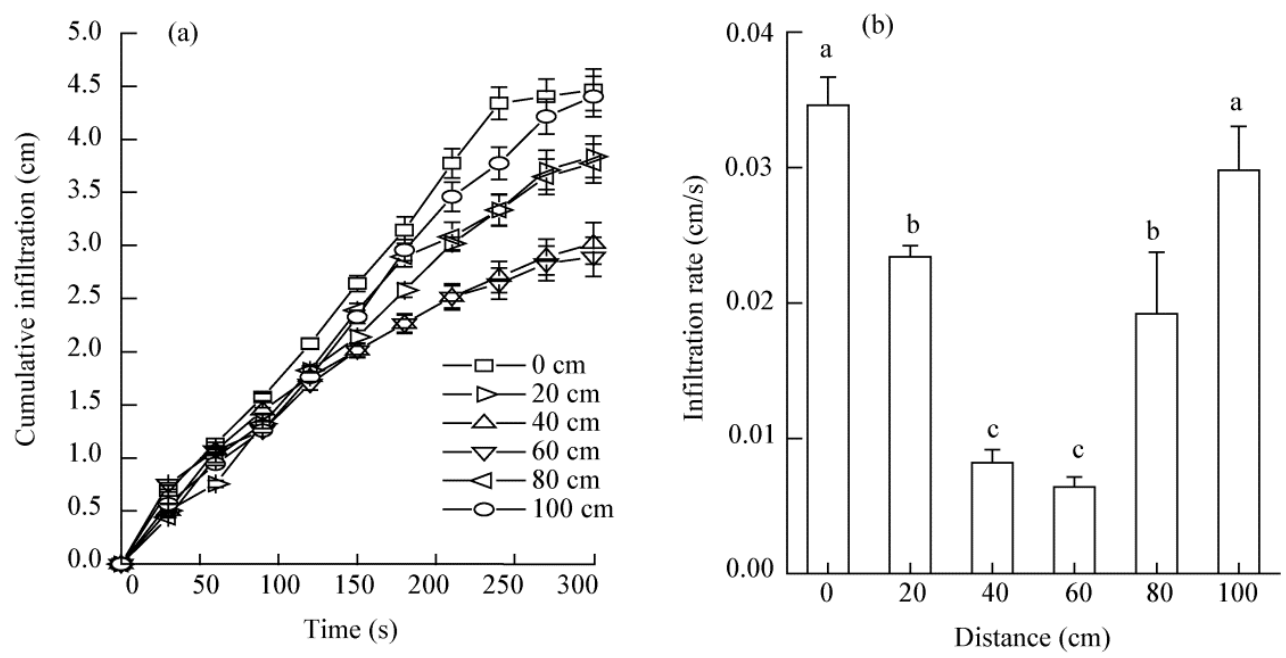

Fig. 7 Cumulative infiltration (a) and infiltration rate (b) at different distances within a straw checkerboard. Different lowercase letters indicate significant differences in infiltration rate at different distances $(P<0.05)$. Bars mean standard errors.
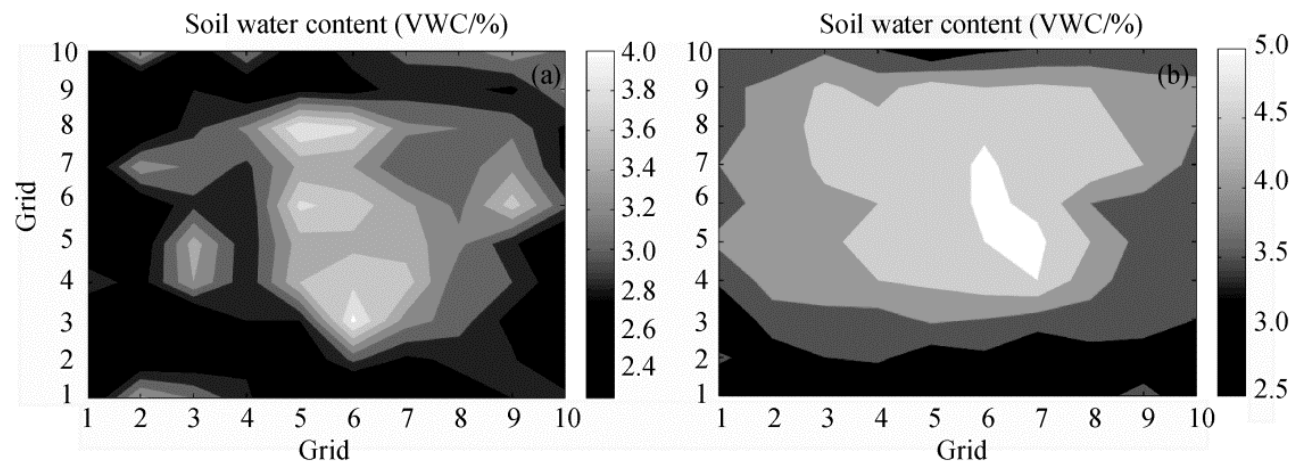

Fig. 8 Soil moisture in the straw checkerboards with A. squarrosum (a) and without A. squarrosum (b) during our experimental period. The $1 \mathrm{~m} \times 1 \mathrm{~m}$ straw checkerboards were divided into 100 equal parts of the $0.1 \mathrm{~m} \times 0.1 \mathrm{~m}$ micro square grids in the surface soil (depth, $0-10 \mathrm{~cm})$.

\section{Discussion}

Micro-geomorphology may be a factor determining the spatial distribution patterns of biodiversity (Davidson et al., 2002; Li et al., 2010). The straw checkerboards, as a key technique for sand stabilization and for desert ecosystem restoration, was reported to be a driving factor for soil heterogeneity, because the establishment of straw checkerboards could enhance the formation of biological soil crusts, reduce wind erosion, and improve the habitat quality for plants (Li et al., 2006). This study demonstrated that a large amount of SOM was produced along the border of straw checkerboards, thus maintaining a sufficient amount of soil nutrients and improving the 
infiltration rate to support the growth of $A$. squarrosum. It was reported that the soil seed banks in the straw checkerboards also exhibited aggregated distributions along the border mainly due to the wind-shelter effect of the straw checkerboarders (Wang et al., 2010). However, the seed bank of $A$. squarrosum had a relatively uniform distribution probably because of the intrinsic factors, such as the size of the seeds. In fact, the seeds of A. squarrosum are larger than other herbaceous plant seeds and larger size may have resulted in small seed dispersion distances.

Previous studies showed that soil moisture was a major driving force in shaping vegetation patterns (Noy-Meir, 1973; Schlesinger et al., 1996), particularly in revegetated desert areas where precipitation was the main source of water replenishment (Rodriguez-Iturbe et al., 2001; Schwinning and Ehleringer, 2001; Li et al., 2013). The spatial patterns in plant species richness and abundance may also be resulted from plant competition when the straw checkerboarders were established. For example, shallow-rooted herbs have advantages over deep-rooted herbs in competition (Li et al., 2004). This study showed that the variation of meteorological factors (such as the monthly precipitation, average air temperature, vapor pressure and relative humidity) were highly correlated with species richness and the abundance of A. squarrosum both in the straw checkerboards and in the sand dunes during the growing season in the experimental period, suggesting that the growth of $A$. squarrosum was mainly determined by the meteorological factors at regional scales. But at micro-geomorphological scales, a large number of A. squarrosum were distributed along the border of the straw checkerboards and almost no plant existed in the center, although the soil moisture in the center was significantly larger than that along the border. In addition, through stepwise regression analysis, we found that the abundance of A. squarrosum was mainly determined by the contents of SOM and total $\mathrm{N}$ and somewhat by soil infiltration rate.

Our results were in agreement with some previous studies in showing that increasing nutrient level can significantly increase the number of annual plants (such as Ceratocarpus arenarius, $S$. ruthenica and Horaninowia ulicina) in sandy arid areas (Boeken et al., 1998; Cross and Schlesinger, 1999; Zhou et al., 2013). But, our results were contradictory with other previous studies in showing that soil moisture was the limiting factor for plant spatial distribution. This contradiction may be reconciled by attributing soil moisture as the first-order and longer-term controlling factor and by attributing the nutrient level as the second-order and shorter-term controlling factor.

\section{Conclusions}

The abundance of $A$. squarrosum decreased exponentially from the border to the center within the straw checkerboards. Soil texture, SOM, soil nutrients (N, P and K) and soil infiltration rate in the topsoil tended to increase outward, while soil moisture presented an opposite tendency. Multiple linear regression analysis suggested that the abundance of A. squarrosum was mainly determined by the contents of SOM and total $\mathrm{N}$ and somewhat by soil infiltration rate, implying that nutrient acclimation was the optimal competitive strategy for $A$. squarrosum surviving in the barren natural environment.

\section{Acknowledgements}

This work was supported by the National Natural Science Foundation of China (41671076, 41530746), the National Basic Research Program of China (2013CB429905) and the Youth Innovation Promotion Association of Chinese Academy of Sciences (2017463). We are grateful to the editor and two anonymous reviewers for their advices on the paper. We would also like to thank Professor XUE Xian for language improvement.

\section{References}

Bai W M, Bao X M, Li L H. 2004. Effects of Agriophyllum squarrosum seed banks on its colonization in a moving sand dune in Hunshandake Sand Land of China. Journal of Arid Environments, 59(1): 151-157.

Boeken B, Lipchin C, Gutterman Y, et al. 1998. Annual plant community responses to density of small-scale soil disturbances in 
the Negev Desert of Israel. Oecologia, 114(1): 106-117.

Bolker B M, Pacala S W, Neuhauser C. 2003. Spatial dynamics in model plant communities: what do we really know?. The American Naturalist, 162(2): 135-148.

Borgogno F, D’Odorico P, Laio F, et al. 2009. Mathematical models of vegetation pattern formation in ecohydrology. Reviews of Geophysics, 47(1): RG1005.

Burke A. 2001. Classification and ordination of plant communities of the Naukluft Mountains, Namibia. Journal of Vegetation Science, 12(1): 53-60.

Chen G X, Zhao J C, Zhao X, et al. 2014. A psammophyte Agriophyllum squarrosum (L.) Moq.: a potential food crop. Genetic Resources and Crop Evolution, 61(3): 669-676.

Cross A F, Schlesinger W H. 1999. Plant regulation of soil nutrient distribution in the northern Chihuahuan Desert. Plant Ecology, 145(1): 11-25.

Davidson D W, Bowker M, George D, et al. 2002. Treatment effects on performance of N-fixing lichens in disturbed soil crusts of the Colorado Plateau. Ecological Applications, 12(5): 1391-1045.

Eccles N S, Esler K J, Cowling R M. 1999. Spatial pattern analysis in Namaqualand desert plant communities: evidence for general positive interactions. Plant Ecology, 142(1-2): 71-85.

Foti R, Ramírez J A. 2013. A mechanistic description of the formation and evolution of vegetation patterns. Hydrology and Earth System Sciences, 17(1): 63-84.

Gordillo-Rivero A J, García-Moreno J, Jordán A, et al. 2014. Fire severity and surface rock fragments cause patchy distribution of soil water repellency and infiltration rates after burning. Hydrological Processes, 28(24): 5832-5843.

HilleRisLambers R, Rietkerk M, van den Bosch F, et al. 2001. Vegetation pattern formation in semi-arid grazing systems. Ecology, 82(1): 50-61.

Huang L, Zhang Z S, Li X R. 2014. Carbon fixation and its influence factors of biological soil crusts in a revegetated area of the Tengger Desert, northern China. Journal of Arid Land, 6(6): 725-734.

Kéfi S, Rietkerk M, Alados C L, et al. 2007. Spatial vegetation patterns and imminent desertification in Mediterranean arid ecosystems. Nature, 449(7159): 213-217.

Klausmeier C A. 1999. Regular and irregular patterns in semiarid vegetation. Science, 284(5421): 1826-1828.

Li X R, Xiao H L, Zhang J G, et al. 2004. Long-term ecosystem effects of sand-binding vegetation in the Tengger Desert, Northern China. Restoration Ecology, 12(3): 376-390.

Li X R, Xiao H L, He M Z, et al. 2006. Sand barriers of straw checkerboards for habitat restoration in extremely arid desert regions. Ecological Engineering, 28(2): 149-157.

Li X R, Kong D S, Tan H J, et al. 2007. Changes in soil and in vegetation following stabilisation of dune in southeastern fringe of the Tengger Desert, China. Plant and Soil, 300: 221-231.

Li X R, He M Z, Zerbe S, et al. 2010. Micro-geomorphology determines community structure of biological soil crusts at small scales. Earth Surface Processes and Landforms, 35(8): 932-940.

Li X R. 2012. Eco-hydrology of Biological Soil Crusts in Desert Regions of China. Beijing: Higher Education Press, $155-170$. (in Chinese)

Li X R, Zhang Z S, Huang L, et al. 2013. Review of the ecohydrological processes and feedback mechanisms controlling sand-binding vegetation systems in sandy desert regions of China. Chinese Science Bulletin, 58(13): 1483-1496.

Liu G S. 1996. Soil Physical and Chemical Analysis and Description of Soil Profiles. Beijing: Standard Press, 121-265. (in Chinese)

Loveland P J, Whalley W R. 2000. Particle size analysis. In: Smith K A, Mullins C. Soil and Environmental Analysis: Physical Methods ( $2^{\text {nd }}$ ed.). New York: Marcel Dekker, Inc.

Ma J L, Liu Z M. 2008. Spatiotemporal pattern of seed bank in the annual psammophyte Agriophyllum squarrosum Moq. (Chenopodiaceae) on the active sand dunes of northeastern Inner Mongolia, China. Plant and Soil, 311(1): $97-107$.

Miao C P, Li X H, Jiang D M. 2013. Spatial variability of Agriophyllum squarrosum across scales and along the slope on an active sand dune in semi-arid China. Arid Land Research and Management, 27(3): 231-244.

Monzeglio U, Stoll P. 2005. Spatial patterns and species performances in experimental plant communities. Oecologia, 145(4): 619-628.

Nanjing Institute of Soil Research. 1978. Analysis of Soil Physicochemical Features. Shanghai: Shanghai Science and Technology Press, 66-208. (in Chinese)

Nelson D W, Sommers L E. 1982. Total carbon, organic carbon, and organic matter. In: Page A L, Miller R H, Keeney D R. Methods of Soil Analysis Part 2: Chemical and Microbiological Properties. Madison, Wisconsin: American Society of Agronomy, Soil Science Society of America, 539-579. 
Nemoto M, Lu X Y. 1992. Ecological characteristics of Agriophyllum squarrosum, a pioneer annual on sand dunes in eastern Inner Mongolia, China. Ecological Research, 7(2): 183-186.

Noy-Meir I. 1973. Desert ecosystems: environment and producers. Annual Review of Ecology and Systematics, 4: $25-51$.

Rietkerk M, Dekker S C, de Ruiter P C, et al. 2004. Self-organized patchiness and catastrophic shifts in ecosystems. Science, 305(5692): 1926-1929.

Rietkerk M, van de Koppel J. 2008. Regular pattern formation in real ecosystems. Trends in Ecology Evolution, 23(3): 169175.

Rodriguez-Iturbe I, Porporato A, Laio F, et al. 2001. Plants in water-controlled ecosystems: active role in hydrologic processes and response to water stress: I. Scope and general outline. Advances in Water Resources, 24(7): 695-705.

Rowe J S, Sheard J W. 1981. Ecological land classification: a survey approach. Environmental Management, 5(5): $451-464$.

Schlesinger W H, Raikes J A, Hartley A E, et al. 1996. On the spatial pattern of soil nutrients in desert ecosystems. Ecology, 77(2): 364-374.

Schurr F M, Bossdorf O, Milton S J, et al. 2004. Spatial pattern formation in semi-arid shrubland: a priori predicted versus observed pattern characteristics. Plant Ecology, 173(2): 271-282.

Schwinning S, Ehleringer J R. 2001. Water use trade-offs and optimal adaptations to pulse-driven arid ecosystems. Journal of Ecology, 89(3): 464-480.

Sherratt J A. 2013. History-dependent patterns of whole ecosystems. Ecological Complexity, 14: 8-20.

Tobe K, Zhang L P, Omasa K. 2005. Seed germination and seedling emergence of three annuals growing on desert sand dunes in China. Annals of Botany, 95(4): 649-659.

Wang X P, Wang Z N, Cui Y, et al. 2010. Variation in soil seed banks composition at the desert microhabitats of Caragana korshinskii shrubs. Arid Land Research and Management, 24(3): 238-252.

Wang Z L, Wang G, Liu X M. 1998. Germination strategy of the temperate sandy desert annual chenopod Agriophyllum squarrosum. Journal of Arid Environments, 40(1): 69-76.

Woodward F I, McKee I F. 1991. Vegetation and climate. Environment International, 17(6): 535-546.

Zhang Z S, Chen Y L, Xu B X, et al. 2015. Topographic differentiations of biological soil crusts and hydraulic properties in fixed sand dunes, Tengger Desert. Journal of Arid Land, 7(2): 205-215.

Zhou X B, Zhang Y M, Niklas K J. 2013. Sensitivity of growth and biomass allocation patterns to increasing nitrogen: a comparison between ephemerals and annuals in the Gurbantunggut Desert, north-western China. Annals of Botany, 113(3): $501-511$. 